\title{
Review
}

\section{Klotho, the Key to Healthy Brain Aging?}

\author{
Hai T. Vo ${ }^{\mathrm{a}}$, Ann M. Laszczyk ${ }^{\mathrm{b}}$ and Gwendalyn D. King ${ }^{\mathrm{a}, *}$ \\ ${ }^{a}$ Department of Neurobiology, University of Alabama at Birmingham, \\ Birmingham, AL, USA \\ ${ }^{\mathrm{b}}$ Department of Cell and Developmental Biology, University of Michigan, Zina Pitcher Pl, \\ Ann Arbor, MI, USA
}

\begin{abstract}
Brain expression of klotho was first described with the initial discovery of the klotho gene. The prominent ageregulating effects of klotho are attributed to regulation of ion homeostasis through klotho function in the kidney. However, recent advances identified brain functions and cell populations, including adult hippocampal neural progenitors, which require klotho. As well, both human correlational studies and mouse models of disease show that klotho is protective against multiple neurological and psychological disorders. This review focuses on current knowledge as to how the klotho protein effects the brain.
\end{abstract}

Keywords: Cognition, synaptic plasticity, long-term potentiation, neurogenesis, white matter, oligodendrocyte, oxidative stress, striatum, aging

\section{KLOTHO, THE FORGOTTEN BRAIN PROTEIN}

The first publication reporting the discovery of klotho (KL) focused on its profound effect regulating lifespan. Deficiency of mouse KL shortened lifespan to only $\sim 8$ weeks (1). KL overexpression causes a $\sim 30 \%$ increase of lifespan, particularly with males (2). While any number of genetic manipulations can affect mouse lifespan, what was particularly profound about the KL-deficient mouse was that short lifespan was accompanied by an array of disorders normally associated with human aging [1]. Between 5 and 8 weeks of age, KL-deficient mice appear to prematurely age, losing muscle and fat mass, undergoing premature thymic involution, developing thin skin, gait abnormalities, infertility, arteriosclerosis, osteoporosis, and emphysema [1]. Many of these

\footnotetext{
*Correspondence to: Gwendalyn King, Ph.D., Department of Neurobiology, University of Alabama at Birmingham, 1825 University Blvd Shelby 913, Birmingham, 35296, AL, USA. Tel.: +1 205996 6247; E-mail: gdking@uab.edu.
}

aging-like disorders result from hyperphosphatemia [1] caused by kidney KL deficiency [3, 4]. KL functions as the fibroblast growth factor 23 co-receptor required for phosphate homeostasis [4] and thus, normal life and healthspan.

Although largely overlooked in the original KLdeficient mouse characterization, $\mathrm{KL}$ is expressed in the brain [1]. KL-deficiency does not recapitulate the pathology of an obvious neurodegenerative disease [1]. However, when learning and memory were tested across KL-deficient mouse lifespan, stunningly rapid onset of cognitive impairment is detected providing the first clue to a functional role for KL expression in the brain [5]. Young, 7 week old KL-deficient mice show hippocampal-dependent memory task impairment only a week after performing equally to age-matched controls [5]. Whether impairment worsens, spreads to modalities beyond the hippocampus, precedes neurodegeneration or aging-like brain pathology is unknown because KL-deficient mice die from peripheral dysfunction shortly after cognitive decline is measured. Moreover, without the ability 
to determine whether cognitive failure was a direct effect of brain-specific KL-deficiency or a secondary outcome of KL mediated cardiovascular or renal failure $[6,7]$, further understanding of KL's role within the brain was limited until recently. With new and growing evidence that KL protein directly regulates multiple brain cell types sufficient to alter brain function, the need to understand the brain-specific actions and therapeutic potential of KL proteins continues to grow.

\section{KLOTHO ESSENTIALS}

In mice, brain expression of KL protein begins in utero [8], increases dramatically after birth and into adulthood [9], and is downregulated with advancing age [10-13]. As with the human protein [14], mouse KL is detected as three distinct forms [15] (Fig. 1). Transmembrane KL is a $130 \mathrm{kDa}$, glycosylated, type 1 , single pass protein with a very short intracellular domain [14-16], that is detected on the surface of cells $[17,18]$. Transmembrane KL protein is predominantly generated by kidney [1]. Brain expression is limited to choroid plexus and neurons $[1,9,19,20]$. Expression in other cells may occur or be species specific [9]; however, antibody specificity concerns have created significant consternation about the reliability of reported localizations beyond neurons and choroid plexus [21]. Transmembrane KL is shed from the cell surface by ADAM10/17 metalloproteinases [22, $23]$ and may be further processed [22, 24]. Shed KL circulates throughout the body through both serum and cerebrospinal fluid (CSF) [16]. In vitro, shedding of KL can be stimulated by insulin [22] or low extracellular calcium [25] but the physiological conditions that increase or decrease shedding are not well understood. The known functions of transmembrane or shed KL derive from peripheral investigations and are well reviewed elsewhere [26-28]. Secreted KL is generated by alternative splicing of KL exon 3 to produce a $70 \mathrm{kDa}$ protein [15]. Secreted KL transcripts are reportedly expressed by the same organs that generate transmembrane KL [14], but in mice, only the brain is reported to make secreted KL protein [29]. Although most of our data about human KL function focuses on the transmembrane protein and its important renal role in ion homeostasis, secreted KL was originally described to be the predominant human RNA transcript [14] and is the major human serum protein form [30]. Yet to date, secreted KL has no known function.

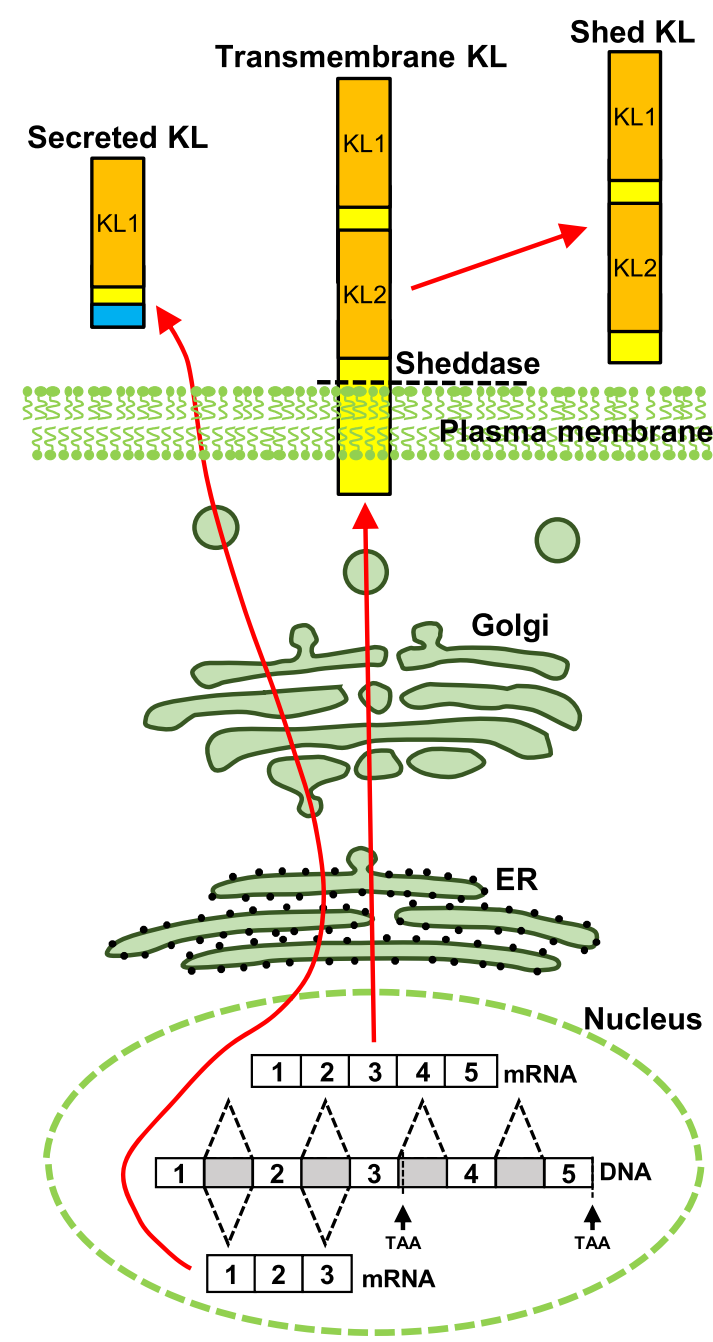

Fig. 1. Schematic depiction of KL protein forms. Transmembrane $\mathrm{KL}$ is transcribed from five exons and localizes to the plasma membrane. Transmembrane KL is shed from the cell surface by ADAM10/17 and circulates through serum and CSF. Alternative splicing of exon three generates secreted KL protein.

\section{THE KL-DEFICIENT BRAIN}

Driven by the initial reports of KL expression within the brain, most initial information about the function of $\mathrm{KL}$ in the brain was derived from study of the KL-deficient mouse brain. In addition to brain RNA expression, the original KLdeficiency paper revealed KL impacts on central nervous system (CNS) function with Parkinsonianlike gait abnormalities and decreased number of Purkinje cells in the cerebellum, an essential region for motor coordination [1]. Further investigations found additional KL-deficient peripheral and CNS 
abnormalities. These included reduction of anterior horn cells and compromised axonal transport [31, 32]. Likewise, when cognitive function was tested across KL-deficient mouse lifespan, no abnormalities were detected until 7 weeks of age when rapid onset of cognitive impairment occurred [5]. At this time point, KL-deficient brains showed increased oxidative stress that, when ameliorated, rescued cognitive dysfunction [5]. Finally, an extensive characterization of terminal 7 week old KL-deficient brain structure using immunohistochemistry and electron microscopy revealed evidence of increased gliosis concomitant with stochastic neurodegeneration [33]. Morphological changes were validated biochemically through measures of altered protein expression including upregulation of the pro-apoptotic marker Bax [5, 33]. Although interesting, the magnitude of these reported cellular and molecular changes are small. Thus, after initial reports, much of the field focused on uncovering the mechanisms behind peripheral KL function where more prominent phenotypes allowed dissection with greater clarity.

\section{HUMANS, KLOTHO, AND COGNITIVE FUNCTION}

Brain immune privilege systems are in place to protect the brain from threats that could be caused by free flow of material and cells from the body into the brain. These create unique challenges for understanding how $\mathrm{KL}$ acts in the brain and how peripheral KL might act upon the brain. The concentration of CSF $\mathrm{KL}$ is consistent with local production rather than transport of serum KL protein, which is too large for passive diffusion across the blood brain barrier [30]. However, CNS KL drainage in CSF could contribute to serum KL levels and mediate KL regulated peripheral systems. Consistent with this idea, one of the two original KL overexpressing mouse lines only overexpressed KL within the brain and such overexpression was sufficient to extend lifespan equivalently to bodywide overexpression [2]. As well, peripheral KL may modulate brain function indirectly through signaling across the blood brain barrier [34].

With mouse studies continuing to suggest that KL expression level correlates with both brain and body health, interest in KL as a human biomarker have provided intriguing correlations to human health and disease. Human serum levels of circulating KL correlate with psychological dysfunction from chronic stress to bipolar disorder [35, 36]. Although CSF KL decreased concomitant with increasing multiple sclerosis disease severity [37], serum KL was unaffected [38]. Patients with temporal lobe epilepsy show less hippocampal KL RNA expression [39]. Meanwhile, when looking for a correlation with Alzheimer's disease, older humans showed lower CSF KL, even less was measured in patients with Alzheimer's, and these effects were greater in women [40]. Consistent with this report, a prospective study found that humans with higher plasma KL showed both higher cognitive assessment scores measured by Mini-Mental State Exam (MMSE) and less decline at follow up exams [41]. Together these indicate that lower brain KL correlates with CNS disease while higher brain KL with CNS health.

Allowing human studies to move beyond correlation of gross serum/CSF KL level and disease state/severity, quite remarkably, two human polymorphic variants of KL correlate with cognitive function. The G395A guanine to adenine polymorphism impacts KL promoter transcription factor binding [42]. Humans under age 60 show no cognitive effect of the polymorphism but those over 60 had a slight but significantly higher IQ and better MMSE score [43]. When humans 90+ years of age were examined, those with the G395A polymorphism were less cognitively impaired and also had higher MMSE scores [44]. Thus, KL transcriptional changes could impact brain function.

An additional polymorphism likewise correlates KL with brain health. More frequently examined, the KL-VS polymorphism is a collection of six single nucleotide polymorphisms, two of which cause KL exon 2 amino acid substitutions (F352V and C370S) [45]. KL-VS may cause increased KL shedding; however, mechanistic studies have only evaluated the effect of the amino acid changing mutations [45, 46]. Longevity, cardiovascular health, and cognitive ability across lifespan reveal KL-VS heterozygote advantage [45, 47, 48]. Initially, KLVS heterozygotes show higher cognitive function across lifespan [48-50] caused, at least in part, by increased dorsolateral prefrontal cortical volume [51]. However, further work using older cohorts report either no such association [52] or even the opposite, KL-VS occurring with increased dementia in men [53] and worse schizophrenic symptomatology [50]. These suggest that the positive effects of KL on cognition may be restricted by time, sex, or other age/disease-related factors yet to be fully elucidated. 


\section{WHAT DO WE KNOW ABOUT KL-MEDIATED EFFECTS ON SPECIFIC BRAIN REGIONS OR CELL POPULATIONS?}

Although global manipulation of KL expression impacts cognitive function, how KL mediates these effects is unclear. Thus, recent work has focused on specific brain regions to help dissect KL mechanism(s) of action.

\section{CEREBELLUM AND CHOROID PLEXUS}

KL is expressed by both choroid plexus epithelial cells and Purkinje neurons of the cerebellum [9, 19, 20]. Little is known about the function of cerebellar KL except that KL-deficient mice have fewer Purkinje neurons and display Parkinsonian-like gait abnormalities [1].

While the brain's ventricles are thought of as open channels of CSF, they contain a very unique, diaphanous tissue, the choroid plexus. Choroid plexus is physically the blood brain barrier and is the major production site of CSF [54]. Gene expression profiling reveals that the choroid plexus more closely resembles the kidney than either the cortex or the hippocampus [55]. This raises the possibility that KL protein could function in choroid plexus as it does in the kidney, to regulate ion homeostasis. Choroid plexus KL protein is localized throughout the cell body and low extracellular calcium concentrations increase choroid plexus KL shedding [25]. In choroid plexus, KL interacts with the $\mathrm{Na}^{+} / \mathrm{K}^{+}$-ATPase, regulating calcium homeostasis through altered membrane abundance of this critical transporter [25]. Although KL-deficient mice have decreased CSF calcium concentrations, they do not display any overt CSF dysfunction like altered osmotic pressure [25]. While this study suggests that KL could be important for the choroid plexus' ability to maintain ion homeostasis, both choroid plexus and cerebellum are understudied KL brain regions.

\section{OLIGODENDROCYTES AND MYELIN}

The brain's white matter tracts, containing neuronal axons, their associated myelin sheaths, and myelin maintaining oligodendrocytes, are particularly prominent sites for downregulation of KL with age $[12,13]$. The volume of the major hippocampal output white matter tract, the fimbria, is dramatically decreased over KL-deficient mouse lifespan and this correlates with fewer oligodendrocytes [56-58]. Axon analysis across CNS white matter tracts of KL-deficient mice show impaired myelination [57]. In vitro experiments reveal a potential role for shed $\mathrm{KL}$ in oligodendrocyte differentiation and maturation [57, 58].

Autoimmune responses to myelin are a pathological feature of multiple sclerosis. In a model of multiple sclerosis, KL overexpressing mice have greater spontaneous central re-myelination [59]. Additionally, KL upregulation occurs after rats are exposed in utero to multiple sclerosis inducing cuprizone [60]. Together these data suggest that KL is important for oligodendrocyte function and myelin sheath maintenance of the normal brain and may be protective under conditions of myelin-related disease. In fact, $\mathrm{KL}$ is also neuroprotective, as in vitro data suggest that it is able to increase resistance to oxidative stress by multiple mechanisms $[61,62]$.

\section{HIPPOCAMPUS}

Although the brain is an integrated unit where a single region never acts in isolation, the hippocampus is a critical nucleus for the brain's learning and memory function. The hippocampus is also intensively studied for its sensitivity to dysfunction caused by normal aging and neurodegenerative diseases. As such, the hippocampus continues to be an important region to understand KL protein function and determine its potential to enhance cognition and memory function.

Early characterization of the KL-deficient hippocampus showed evidence of increased oxidative stress, increased markers of apoptosis and increased stochastic neuron death [5, 33]. Importantly, performance using hippocampal-dependent learning and memory tasks showed rapid onset of cognitive impairment between the 6th and 7th week of life [5]. KL-deficient mice die between 8 and 12 weeks of age such that 7 week old KL-deficient mice are in terminal decline. With the inability to clarify whether peripheral disease confounds these results, evaluation of the KL overexpressing brain provided critical evidence supporting the brain-specific role of KL. In addition to confirming that KL overexpression extends lifespan [49], recent work measured enhanced hippocampal-dependent task performance that protects from age-related cognitive decline $[56,63]$. As well, KL overexpression in a model 
of Alzheimer's disease both extends lifespan and enhances cognition [63]. Together, global models of KL expression indicate that KL protein affects hippocampal function; however, neither the KL form nor the cellular/molecular mechanisms of KL action are well elucidated. Further complexity is added by the recent discovery that the brain is the only murine site where secreted KL is detected, with RNA and protein expression found throughout neuronal rich regions of the brain [29]. Increased ventricular circulation by viral vector expression of secreted KL is sufficient to enhance hippocampal-dependent cognitive function [64]. Together these results establish the importance of KL for normal cognitive function, although mechanistic interrogation of all forms of KL remains to be accomplished. Our recent studies have begun to define distinct neuronal processes that KL regulates.

\section{ADULT HIPPOCAMPAL NEUROGENESIS, AGING, AND KLOTHO}

Generation of new adult neurons takes place through a series of transcriptional and morphological changes as radial glia-like stem cells commit to a neuronal fate and then mature and integrate into the circuit $[65,66]$. The hippocampal dentate gyrus is one of a few brain regions where neurogenesis continues throughout adulthood; however, neurogenic decline may be the first brain "aging" phenotype. Following postnatal development of the mammalian brain, neurogenesis rapidly decreases during early adulthood, falling to a low, steady state that continues through old age [67, 68]. In rodents, the number of actively dividing progenitors decreases by $90 \%$ between $3-$ and 20-months [69-72]. Neuronal commitment and differentiation are also altered with age. Four weeks after labeling dividing progenitors, middle age brains show $40 \%$ fewer cells expressing neuronal protein markers compared to young mice [73, 74], suggesting that either the fraction of cells committed to a neuronal fate decreases with age or that the entire process is much slower in aged brain.

While elucidation of mechanisms underlying agerelated loss of neurogenesis are ongoing, evidence proposes that age-related neurogenic decline could be reversible. Heterochronic parabiosis or young serum transfusions restore aged mouse progenitor proliferation and survival [75-78]. These suggest that rather than an intrinsic change in aged progenitor cells, age-related neurogenic decline is a response to a changing niche microenvironment. Indeed, individual extracellular growth factors, many of which are age-downregulated, can improve aspects of adult neurogenesis [79-86]. However, rescue of age-related neurogenic decline will not be as simple as increasing the concentration of age-downregulated growth factors alone, as maintenance of the progenitor pool throughout life is dependent upon an appropriate balance between factors that promote progenitor proliferation and quiescence. For example growth factors FGF-2 and IGF-1 promote proliferation and production of new neurons, but hyperactive signaling prematurely depletes the progenitor pool [87-90]. Beyond progenitor maintenance, survival of new neurons is also modulated by growth factors. Hippocampal granule neuron or progenitor cell derived bone morphogenic proteins both promote progenitor quiescence and stimulate differentiation $[88,91]$ while brain-derived neurotrophic factor promotes both proliferation and survival of new neurons [92-95]. Thus, a network of extracellular factors promote neuron production while at the same time maintaining the progenitor pool $[94,95]$.

Neurogenic changes within the hippocampus can affect learning and memory [76, 96-99], raising the possibility that the effect of KL on hippocampaldependent cognition $[49,63,100]$ could be caused, at least in part, by a regulatory role for KL in adult neurogenesis [56]. We recently used KL-deficient and KL overexpressing mice to test this idea. Whereas KL overexpression enhances neurogenesis into at least early adulthood, KL-deficient brains undergo rapid collapse of the hippocampal neurogenic niche [56]. Both models provide evidence that KL affects proliferation and maturation of neural progenitors (Fig. 2). Of note, KL-deficient mouse progenitor proliferation is reduced as early as 3 weeks of age [56], prior to body-wide deterioration [1]. Thus, while some argue KL brain phenotypes are a secondary effect of toxic hyperphosphatemia [1], this neurogenic change prior to overt peripheral dysfunction supports a direct role of brain KL. Furthermore, reduced proliferation of the KL-deficient neurogenic niche is recapitulated in vitro using KL-deficient neurospheres. Culture media supplemented with recombinant shed KL, caused a complete rescue of proliferation [56]. As progenitors do not express KL [56], this identifies a non-cell autonomous function for shed KL on the earliest neural progenitors.

BrdU labeling of KL-deficient dentate progenitors shows that newly committed neurons fail to fully mature [56]. KL-deficient mice exhibit not only a 


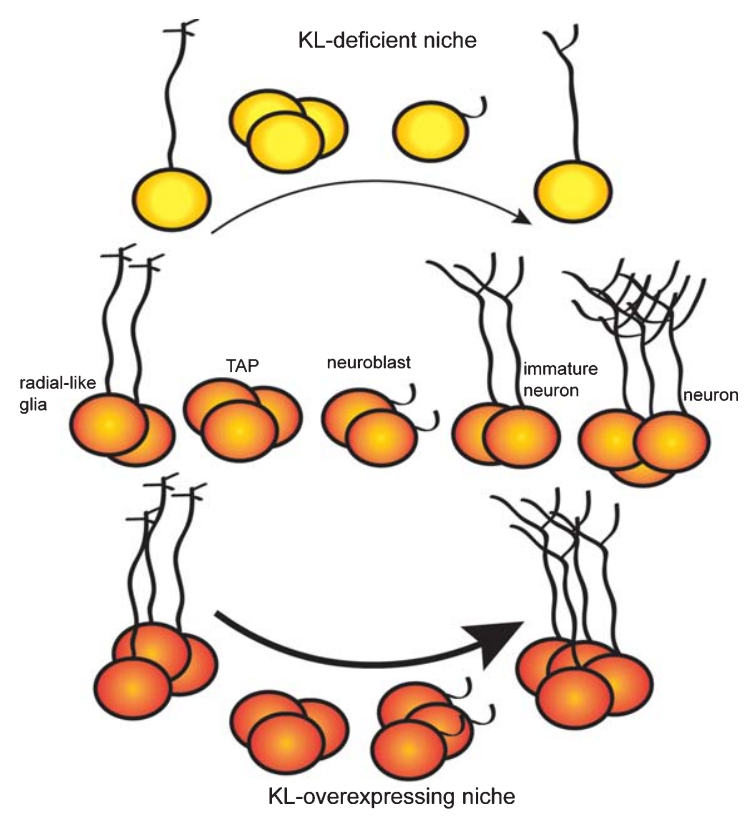

Fig. 2. KL expression regulates dentate adult neurogenesis. Adult neurogenesis occurs as radial glial-like stem cells progress through a series of protein expression and morphological changes to advance from transient amplifying cells (TAP), to committed neuroblasts, to immature neurons and finally fully mature neurons. KL-deficient brains show premature neurogenic aging with decreased proliferation, decreased number of stem cells and immature neurons, and delayed maturation of immature neurons. KL overexpression increases proliferation and enhances maturation causing a greater number of highly arborized immature neurons to persist long after normal age-related downregulation of adult neurogenesis.

reduced number of immature neurons, but also poor dendritic arborization and aberrant transcriptional changes indicative of stalled maturation [56]. Conversely, KL overexpressing hippocampi hold more immature neurons and these have enhanced dendritic arborization [56]. Consistent with cellular data, KL overexpression shows increased expression of immature neuron glutamate receptor subunit, GluN2B [49] which could either indicate that the receptor subunit composition of mature neurons is different [101, 102] and/or that there are more GluN2B expressing immature neurons [103, 104]. While the temporal expression of KL during neuronal maturation is unknown, $\mathrm{KL}$ is expressed by mature neurons including granule neurons $[9,18,105]$. This suggests that mature neuronal function requires KL. While hippocampus hosts all three forms of KL protein and evidence exists for shed KL acting on progenitors, further work is required to understand which forms and by what mechanism do the KL proteins regulate neuronal maturation.

\section{KLOTHO AND HIPPOCAMPAL SYNAPTIC PLASTICITY}

Across labs and memory protocols, KL-deficient mice exhibit cognitive deficits and KL overexpressing mice exhibit enhanced cognition with learning and memory tasks that require the hippocampus [5, 49, 56]. KL-deficient brain lysates show reduced expression of the presynaptic marker synaptophysin and total synapse number [19, 33]. Also, KL is expressed by hippocampal neurons $[9,18,19]$ and recent subcellular fractionation of total hippocampal lysates indicate that transmembrane $\mathrm{KL}$ localizes to membrane and synaptic fractions [18]. Localization and functional indicators suggest cellautonomous function of KL could directly affect synaptic plasticity. But, it is also important to note that with CSF circulating, shed KL [16] and secreted KL are detected across the brain parenchyma [29], thus non-cell autonomous regulation of plasticity could occur. To begin investigation of KL effects on synaptic plasticity, KL-deficient hippocampal Schaffer collateral projections were measured using 7 week old, terminal mice. Decreased longterm potentiation was only detected with a very light stimulation protocol $[18,106]$. However, KLdeficient mice measured before the onset of cognitive impairment (5 weeks) show enhanced paired-pulse facilitation and long-term potentiation, indicators of pre- and post-synaptic function, respectively. These changes occur with no detectable change in baseline synaptic transmission, strongly suggesting that KL specifically regulates plasticity [18]. Additionally, we found that acute application of recombinant shed KL to slice culture buffer had no effect on paired-pulse facilitation suggesting that shed KL, at least acutely, does not impact plasticity [18]. While enhanced paired-pulse facilitation, long-term potentiation, and impaired memory are a very rare phenotypic combination, examples exist that may implicate dysfunction of protein interactions at the synapse [107].

Synaptic plasticity data from KL overexpressing mice are conflicting. We tested KL overexpressing Schaffer collateral synapses at 2 or 6 months to measure synaptic plasticity before and after the onset of cognitive enhancement. Only older, 6 month old KL overexpressing mice show decreased long-term potentiation with no effect on paired-pulse facilitation [18]. However, other reports show enhanced long-term potentiation at both the Schaffer collateral [34] and mossy fiber synapses [49] that is 
blocked by inhibition of the GluN2B glutamate receptor subunit [49]. This result is consistent with GluN2B overexpressing mice that exhibit enhanced synaptic plasticity and memory behaviors [102]. Interlab electrophysiological discrepancies can result from different stimulation and/or recording protocols. Likewise, these studies used different ages of mice. Thus, clarity about the role of KL in synaptic plasticity will require detailed mechanistic interrogation. This need is further reinforced by fascinating data that show elevated long-term potentiation at Schaffer collateral synapses is possible simply by injecting recombinant shed KL into the periphery [34]. As KL does not cross the blood brain barrier [34], these data raise the intriguing possibility that peripheral signaling could impact synaptic plasticity and further emphasize the need for molecular level detail of the function of all forms of KL, particularly as they relate to regulation of synaptic plasticity.

\section{DOPAMINERGIC NEURONS}

While hippocampal studies point to a role of $\mathrm{KL}$ in regulation of oxidative stress [5], the ability of KL to decrease oxidative stress and thus provide neuroprotection is also reported for dopaminergic neurons of the substantia nigra pars compacta and ventral tegmental area [108]. Dopaminergic neurons are particularly sensitive to aging processes and are the critical cells lost during Parkinson's disease development [109]. With age, KL-deficient mice show selective loss of dopaminergic neurons and their neurotransmitter, dopamine, a phenotype that can be rescued by reducing Vitamin D levels [108]. Lysates from either KL-deficient or KL overexpressing brains reveal reciprocal effects on p38 MAPK signal activation, which increases in response to oxidative stress [110]. Increased p38 activation is the result of free apoptosis signal-regulating kinase 1 which is inhibited when bound in a complex with thioredoxin and 14-3-3 $\zeta$. KL-deficiency favors the dissociation of the inhibitory complex while overexpression of KL favors complex formation [110, 111]. These studies identify a previously unidentified KL-modulated stress pathway with the potential to impact neurodegeneration. In vivo, genetic and multiple chemical models of Parkinson's disease show protection from dopaminergic neuron loss, motor, and cognitive symptoms when KL is increased [108, $110,112]$.

\section{KLOTHO AND PITUITARY GLAND}

Although the CNS component of the hypothalamic-pituitary-adrenal (HPA) axis does not express KL [113], KL-deficient mice show HPA axis dysfunction causing a wide range of peripheral problems beyond the scope of this review. However, KL mRNA is detected in the pituitary gland and KL-deficient mouse pituitary cells responsible for hormone secretion are abnormally small [1]. Grossly HPA dysfunction manifests as growth retardation, gonadal atrophy, and infertility [1]. Atrophy and infertility is not caused by KL-deficiency in sex organs [113], rather the KL-deficient pituitary produces insufficient levels of the critical hormones required for sexual maturity (ex. growth hormone, luteinizing hormone, and follicle-stimulating hormone) $[1,113]$. This is likely a function of shed KL as growth hormone secretion occurs in response to shed KL [114].

\section{TOWARD THERAPEUTIC TARGETING OF KL}

$\mathrm{KL}$ is a pleotropic brain protein (Fig. 3). Choroid plexus expresses the highest KL levels and is thus the likely greatest source of extracellular KL protein $[9,16,19,20]$. Choroid plexus may require KL for homeostatic mechanisms [25]. Although understudied, cerebellar expression likely accounts for KL-deficient mouse motor deficits [1]. KL protects oligodendrocytes and neurons from the deadly effects of oxidative stress and also functions to promote proper maturation of both cell types in adult brain [5, 33, 56-59, 61]. KL regulates hippocampal functions from cognition $[5,34,49,57]$, to neurogenesis [56], to synaptic plasticity $[18,34,49,106]$ and thus holds potential to function as a novel therapeutic target to protect this sensitive brain region from both the deleterious effects of normal aging and the ravages of neurodegenerative diseases like Alzheimer's disease [63].

Work is ongoing to identify small molecule modulators of KL [115], use recombinant KL protein [34], and gene therapeutic approaches [64] as novel therapies to support brain health. While multiple models of KL overexpression have so far provided strong indications that $\mathrm{KL}$ is a brain-wide protective protein that could enhance brain health with age and positively impact an array of neurodegenerative diseases [35, $56,63,64]$, there is still much that must be understood 


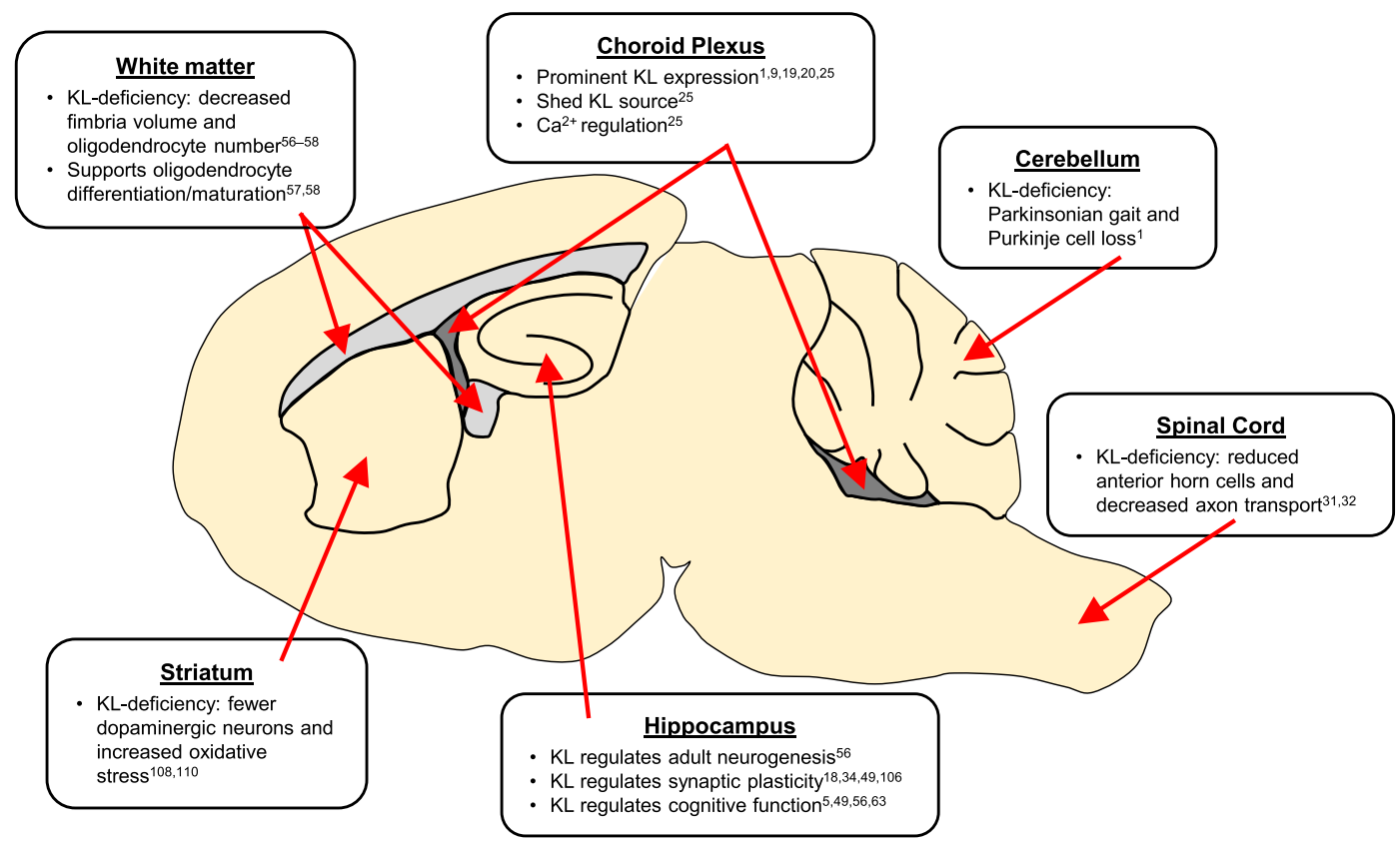

Fig. 3. Summary of KL implicated brain regions. KL proteins act throughout neuronal and non-neuronal regions of the brain.

about KL before confidence in its therapeutic targeting is justified. First, replication of critical data by independent labs is required especially when KL supplementation appears to have profound and always positive effects. Second, the majority of mechanistic studies involving KL use single time points and/or doses to assess and interpret results. Human studies warn that KL may have a narrow time [52] and concentration window of therapeutic efficacy before it causes disease on its own [116]. Even the addition of one additional time point can dramatically impact data interpretation as was the case in our recent work showing that KL overexpression doesn't simply elevate memory, it prevents decline [56]. Additionally, studies conducted to date have used almost exclusively mice in the first half of lifespan. Knowing that the aged brain is fundamentally a different environment, it is critical that data show the normal role of KL in aged brain and at ages when therapeutic modeling is most relevant.

Whether warranted or not, KL's seeming ability to improve everything it touches in the brain, elicits skepticism that can only be eliminated with more, high quality, rigorously controlled mechanistic studies. These will be enabled by development of more refined genetic models as well as development of tools to allow precise mechanistic studies of specific KL forms and brain-specific KL mechanisms of action. Untangling the direct and indirect functions of KL within the brain will allow targeted therapeutic investment in specific disease modalities. In the meantime, an array of questions and brain areas remain to be explored to understand the basic biology of the KL protein and how its various forms act to support healthy life and healthy aging.

\section{ACKNOWLEDGMENTS}

This work was funded in part by NIH/NIA R56AG052936 (GDK).

\section{CONFLICTS OF INTEREST}

The authors have no conflicts of interest to report.

\section{REFERENCES}

[1] Kuro-o M, Matsumura Y, Aizawa H, Kawaguchi H, Suga T, Utsugi T, et al. Mutation of the mouse klotho gene leads to a syndrome resembling ageing. Nature. 1997;390(6655):45-51.

[2] Kurosu H, Yamamoto M, Clark JD, Pastor JV, Nandi A, Gurnani P, et al. Suppression of aging in mice by the hormone Klotho. Science. 2005;309(5742):1829-33.

[3] Urakawa I, Yamazaki Y, Shimada T, Iijima K, Hasegawa $\mathrm{H}$, Okawa $\mathrm{K}$, et al. Klotho converts canonical FGF receptor into a specific receptor for FGF23. Nature. 2006;444(7120):770-74.

[4] Kurosu H, Ogawa Y, Miyoshi M, Yamamoto M, Nandi A, Rosenblatt KP, et al. Regulation of fibroblast 
growth factor-23 signaling by klotho. J Biol Chem. 2006;281(10):6120-3.

[5] Nagai T, Yamada K, Kim H-C, Kim Y-S, Noda Y, Imura A, et al. Cognition impairment in the genetic model of aging klotho gene mutant mice: A role of oxidative stress. FASEB J. 2003;17(1):50-2.

[6] Hermann DM, Kribben A, Bruck H. Cognitive impairment in chronic kidney disease: Clinical findings, risk factors and consequences for patient care. J Neural Transm. 2014;121(6):627-32.

[7] Picano E, Bruno RM, Ferrari GF, Bonuccelli U. Cognitive impairment and cardiovascular disease: So near, so far. Int J Cardiol. 2014;175(1):21-9.

[8] Takeshita K, Fujimori T, Kurotaki Y, Honjo H, Tsujikawa $\mathrm{H}$, Yasui K, et al. Sinoatrial node dysfunction and early unexpected death of mice with a defect of klotho gene expression. Circulation. 2004;109(14):1776-82.

[9] Clinton SM, Glover ME, Maltare A, Laszczyk AM, Mehi SJ, Simmons RK, et al. Expression of klotho mRNA and protein in rat brain parenchyma from early postnatal development into adulthood. Brain Res. 2013;1527:1-14.

[10] Xiao N, Zhang Y, Zheng Q, Gu J. Klotho is a serum factor related to human aging. Chin Med J. 2004;117(5):742-7.

[11] Yamazaki Y, Imura A, Urakawa I, Shimada T, Murakami J, Aono Y, et al. Establishment of sandwich ELISA for soluble alpha-Klotho measurement: Age-dependent change of soluble alpha-Klotho levels in healthy subjects. Biochem Biophys Res Commun. 2010;398(3):513-8.

[12] Duce JA, Podvin S, Hollander W, Kipling D, Rosene DL, Abraham CR. Gene profile analysis implicates Klotho as an important contributor to aging changes in brain white matter of the rhesus monkey. Glia. 2008;56(1): 106-17.

[13] King GD, Rosene DL, Abraham CR. Promoter methylation and age-related downregulation of Klotho in rhesus monkey. Age (Dordr). 2012;34(6):1405-19.

[14] Matsumura Y, Aizawa H, Shiraki-Iida T, Nagai R, Kuroo M, Nabeshima Y. Identification of the human klotho gene and its two transcripts encoding membrane and secreted klotho protein. Biochem Biophys Res Commun. 1998;242(3):626-30.

[15] Shiraki-Iida T, Aizawa H, Matsumura Y, Sekine S, Iida A, Anazawa H, et al. Structure of the mouse klotho gene and its two transcripts encoding membrane and secreted protein. FEBS Lett. 1998;424(1-2):6-10.

[16] Imura A, Iwano A, Tohyama O, Tsuji Y, Nozaki K, Hashimoto N, et al. Secreted Klotho protein in sera and CSF: Implication for post-translational cleavage in release of Klotho protein from cell membrane. FEBS Lett. 2004;565(1-3):143-7.

[17] Kato Y, Arakawa E, Kinoshita S, Shirai A, Furuya $\mathrm{A}$, Yamano $\mathrm{K}$, et al. Establishment of the antiKlotho monoclonal antibodies and detection of Klotho protein in kidneys. Biochem Biophys Res Commun. 2000;267(2):597-602

[18] Li Q, Vo HT, Wang J, Fox-Quick S, Dobrunz LE, King GD. Klotho regulates CA1 hippocampal synaptic plasticity. Neuroscience. 2017;347:123-33.

[19] Li S-A, Watanabe M, Yamada H, Nagai A, Kinuta M, Takei K. Immunohistochemical localization of Klotho protein in brain, kidney, and reproductive organs of mice. Cell Struct Funct. 2004;29(4):91-9.

[20] German DC, Khobahy I, Pastor J, Kuro-O M, Liu X. Nuclear localization of Klotho in brain: An anti-aging protein. Neurobiol Aging. 2012;33(7):1483.e25-30.
[21] Olauson H, Mencke R, Hillebrands J-L, Larsson TE. Tissue expression and source of circulating $\alpha$ Klotho. Bone. 2017;100:19-35.

[22] Chen C-D, Podvin S, Gillespie E, Leeman SE, Abraham CR. Insulin stimulates the cleavage and release of the extracellular domain of Klotho by ADAM10 and ADAM17. Proc Natl Acad Sci U S A. 2007;104(50):19796-801.

[23] Chen C-D, Tung TY, Liang J, Zeldich E, Tucker Zhou TB, Turk BE, et al. Identification of cleavage sites leading to the shed form of the anti-aging protein klotho. Biochemistry. 2014;53(34):5579-87.

[24] Van Loon EPM, Pulskens WP, van der Hagen EAE, Lavrijsen M, Vervloet MG, van Goor H, et al. Shedding of klotho by ADAMs in the kidney. Am J Physiol Renal Physiol. 2015;309(4):F359-68.

[25] Imura A, Tsuji Y, Murata M, Maeda R, Kubota K, Iwano A, et al. alpha-Klotho as a regulator of calcium homeostasis. Science. 2007;316(5831):1615-8.

[26] Xu Y, Sun Z. Molecular basis of Klotho: From gene to function in aging. Endocr Rev. 2015;36(2):174-93.

[27] Hu MC, Kuro-o M, Moe OW. Renal and extrarenal actions of Klotho. Semin Nephrol. 2013;33(2):118-29.

[28] Kim J-H, Hwang K-H, Park K-S, Kong ID, Cha S-K. Biological Role of Anti-aging Protein Klotho. J Lifestyle Med. 2015;5(1):1-6.

[29] Massó A, Sánchez A, Gimenez-Llort L, Lizcano JM, Cañete M, García B, et al. Secreted and Transmembrane $\alpha$ Klotho Isoforms Have Different Spatio-Temporal Profiles in the Brain during Aging and Alzheimer's Disease Progression. PLoS One. 2015;10(11):e0143623.

[30] Kunert SK, Hartmann H, Haffner D, Leifheit-Nestler M. Klotho and fibroblast growth factor 23 in cerebrospinal fluid in children. J Bone Miner Metab. 2017;35(2):215-26.

[31] Anamizu Y, Kawaguchi H, Seichi A, Yamaguchi S, Kawakami E, Kanda N, et al. Klotho insufficiency causes decrease of ribosomal RNA gene transcription activity, cytoplasmic RNA and rough ER in the spinal anterior horn cells. Acta Neuropathol. 2005;109(5): 457-66.

[32] Uchida A, Komiya Y, Tashiro T, Yorifuji H, Kishimoto T, Nabeshima Y, et al. Neurofilaments of Klotho, the mutant mouse prematurely displaying symptoms resembling human aging. J Neurosci Res. 2001;64(4):364-70.

[33] Shiozaki M, Yoshimura K, Shibata M, Koike M, Matsuura $\mathrm{N}$, Uchiyama Y, et al. Morphological and biochemical signs of age-related neurodegenerative changes in klotho mutant mice. Neuroscience. 2008;152(4):924-41.

[34] Leon J, Moreno AJ, Garay BI, Chalkley RJ, Burlingame AL, Wang D, et al. Peripheral Elevation of a Klotho Fragment Enhances Brain Function and Resilience in Young, Aging, and $\alpha$-Synuclein Transgenic Mice. Cell Rep. 2017;20(6):1360-71.

[35] Prather AA, Epel ES, Arenander J, Broestl L, Garay BI, Wang D, et al. Longevity factor klotho and chronic psychological stress. Transl Psychiatry. 2015;5:e585.

[36] Barbosa IG, Rocha NP, Alpak G, Vieira ELM, Huguet RB, Rocha FL, et al. Klotho dysfunction: A pathway linking the aging process to bipolar disorder? J Psychiatr Res. 2017;95:80-3.

[37] Emami Aleagha MS, Siroos B, Ahmadi M, Balood M, Palangi A, Haghighi AN, et al. Decreased concentration of Klotho in the cerebrospinal fluid of patients with relapsing-remitting multiple sclerosis. J Neuroimmunol. 2015;281:5-8. 
[38] Ahmadi M, Emami Aleagha MS, Harirchian MH, Yarani R, Tavakoli F, Siroos B. Multiple sclerosis influences on the augmentation of serum Klotho concentration. J Neurol Sci. 2016;362:69-72.

[39] Teocchi MA, Ferreira AÉD, da Luz de Oliveira EP, Tedeschi H, D’Souza-Li L. Hippocampal gene expression dysregulation of Klotho, nuclear factor kappa B and tumor necrosis factor in temporal lobe epilepsy patients. J Neuroinflammation. 2013;10:53.

[40] Semba RD, Moghekar AR, Hu J, Sun K, Turner R, Ferrucci $\mathrm{L}$, et al. Klotho in the cerebrospinal fluid of adults with and without Alzheimer's disease. Neurosci Lett. 2014;558:3740.

[41] Shardell M, Semba RD, Rosano C, Kalyani RR, Bandinelli $\mathrm{S}$, Chia CW, et al. Plasma klotho and cognitive decline in older adults: Findings from the inchianti study. J Gerontol A Biol Sci Med Sci. 2016;71(5):677-82.

[42] Kawano K, Ogata N, Chiano M, Molloy H, Kleyn P, Spector TD, et al. Klotho gene polymorphisms associated with bone density of aged postmenopausal women. J Bone Miner Res. 2002;17(10):1744-51.

[43] Shimokata H, Ando F, Fukukawa Y, Nishita Y. Klotho gene promoter polymorphism and cognitive impairment. Geriatr Gerontol Int. 2006;6(2):136-41.

[44] Hao Q, Ding X, Gao L, Yang M, Dong B. G-395A polymorphism in the promoter region of the KLOTHO gene associates with reduced cognitive impairment among the oldest old. Age (Dordr). 2016;38(1):7

[45] Arking DE, Krebsova A, Macek M, Macek M, Arking A, Mian IS, et al. Association of human aging with a functional variant of klotho. Proc Natl Acad Sci U S A. 2002;99(2):856-61.

[46] Tucker Zhou TB, King GD, Chen C, Abraham CR. Biochemical and functional characterization of the klotho-VS polymorphism implicated in aging and disease risk. J Biol Chem. 2013;288(51):36302-11.

[47] Arking DE, Atzmon G, Arking A, Barzilai N, Dietz HC. Association between a functional variant of the KLOTHO gene and high-density lipoprotein cholesterol, blood pressure, stroke, and longevity. Circ Res. 2005;96(4): 412-8.

[48] Deary IJ, Harris SE, Fox HC, Hayward C, Wright AF, Starr JM, et al. KLOTHO genotype and cognitive ability in childhood and old age in the same individuals. Neurosci Lett. 2005;378(1):22-7.

[49] Dubal DB, Yokoyama JS, Zhu L, Broestl L, Worden K, Wang D, et al. Life extension factor klotho enhances cognition. Cell Rep. 2014;7(4):1065-76.

[50] Morar B, Badcock JC, Phillips M, Almeida OP, Jablensky A. The longevity gene Klotho is differentially associated with cognition in subtypes of schizophrenia. Schizophr Res. 2017.

[51] Yokoyama JS, Sturm VE, Bonham LW, Klein E, Arfanakis $\mathrm{K}$, Yu L, et al. Variation in longevity gene KLOTHO is associated with greater cortical volumes. Ann Clin Transl Neurol. 2015;2(3):215-30.

[52] Mengel-From J, Soerensen M, Nygaard M, McGue M, Christensen K, Christiansen L. Genetic variants in KLOTHO associate with cognitive function in the oldest old group. J Gerontol A Biol Sci Med Sci. 2016;71(9):1151-9.

[53] Almeida OP, Morar B, Hankey GJ, Yeap BB, Golledge J, Jablensky A, et al. Longevity Klotho gene polymorphism and the risk of dementia in older men. Maturitas. 2017;101:1-5.
[54] Lun MP, Monuki ES, Lehtinen MK. Development and functions of the choroid plexus-cerebrospinal fluid system. Nat Rev Neurosci. 2015;16(8):445-57.

[55] Sathyanesan M, Girgenti MJ, Banasr M, Stone K, Bruce $\mathrm{C}$, Guilchicek E, et al. A molecular characterization of the choroid plexus and stress-induced gene regulation. Transl Psychiatry. 2012;2:e139.

[56] Laszczyk AM, Fox-Quick S, Vo HT, Nettles D, Pugh PC, Overstreet-Wadiche L, et al. Klotho regulates postnatal neurogenesis and protects against age-related spatial memory loss. Neurobiol Aging. 2017;59:41-54.

[57] Chen C-D, Li H, Liang J, Hixson K, Zeldich E, Abraham CR. The anti-aging and tumor suppressor protein Klotho enhances differentiation of a human oligodendrocytic hybrid cell line. J Mol Neurosci. 2015;55(1):76-90.

[58] Chen C-D, Sloane JA, Li H, Aytan N, Giannaris EL, Zeldich $\mathrm{E}$, et al. The antiaging protein Klotho enhances oligodendrocyte maturation and myelination of the CNS. J Neurosci. 2013;33(5):1927-39.

[59] Zeldich E, Chen C-D, Avila R, Medicetty S, Abraham CR. The Anti-Aging Protein Klotho Enhances Remyelination Following Cuprizone-Induced Demyelination. J Mol Neurosci. 2015;57(2):185-96.

[60] Abe H, Saito F, Tanaka T, Mizukami S, Hasegawa-Baba Y, Imatanaka N, et al. Developmental cuprizone exposure impairs oligodendrocyte lineages differentially in cortical and white matter tissues and suppresses glutamatergic neurogenesis signals and synaptic plasticity in the hippocampal dentate gyrus of rats. Toxicol Appl Pharmacol. 2016;290:10-20.

[61] Zeldich E, Chen C-D, Colvin TA, Bove-Fenderson EA, Liang J, Tucker Zhou TB, et al. The neuroprotective effect of Klotho is mediated via regulation of members of the redox system. J Biol Chem. 2014;289(35):24700-15.

[62] Cheng M-F, Chen L-J, Niu H-S, Yang T-T, Lin K-C, Cheng J-T. Signals mediating Klotho-induced neuroprotection in hippocampal neuronal cells. Acta Neurobiol Exp (Wars). 2015;75(1):60-71.

[63] Dubal DB, Zhu L, Sanchez PE, Worden K, Broestl L, Johnson E, et al. Life extension factor klotho prevents mortality and enhances cognition in hAPP transgenic mice. J Neurosci. 2015;35(6):2358-71.

[64] Massó A, Sánchez A, Bosch A, Giménez-Llort L, Chillón M. Secreted $\alpha$ Klotho isoform protects against agedependent memory deficits. Mol Psychiatry. 2017.

[65] Duan X, Kang E, Liu CY, Ming G-L, Song H. Development of neural stem cell in the adult brain. Curr Opin Neurobiol. 2008;18(1):108-15.

[66] Kempermann G, Song H, Gage FH. Neurogenesis in the adult hippocampus. Cold Spring Harb Perspect Biol. 2015;7(9):a018812.

[67] Seki T, Arai Y. Age-related production of new granule cells in the adult dentate gyrus. Neuroreport. 1995;6(18):247982.

[68] Kuhn HG, Dickinson-Anson H, Gage FH. Neurogenesis in the dentate gyrus of the adult rat: Age-related decrease of neuronal progenitor proliferation. J Neurosci. 1996;16(6):2027-33.

[69] Kempermann G, Gast D, Gage FH. Neuroplasticity in old age: Sustained fivefold induction of hippocampal neurogenesis by long-term environmental enrichment. Ann Neurol. 2002;52(2):135-43.

[70] Tropepe V, Craig CG, Morshead CM, van der Kooy D. Transforming growth factor-alpha null and senescent mice show decreased neural progenitor cell proliferation 
in the forebrain subependyma. J Neurosci. 1997;17(20): 7850-9.

[71] Heine VM, Maslam S, Joëls M, Lucassen PJ. Prominent decline of newborn cell proliferation, differentiation, and apoptosis in the aging dentate gyrus, in absence of an age-related hypothalamus-pituitary-adrenal axis activation. Neurobiol Aging. 2004;25(3):361-75.

[72] McDonald HY, Wojtowicz JM. Dynamics of neurogenesis in the dentate gyrus of adult rats. Neurosci Lett. 2005;385(1):70-5.

[73] Kempermann G, Kuhn HG, Gage FH. Experience-induced neurogenesis in the senescent dentate gyrus. J Neurosci. 1998;18(9):3206-12.

[74] Bondolfi L, Ermini F, Long JM, Ingram DK, Jucker M. Impact of age and caloric restriction on neurogenesis in the dentate gyrus of C57BL/6 mice. Neurobiol Aging. 2004;25(3):333-40.

[75] Katsimpardi L, Litterman NK, Schein PA, Miller CM, Loffredo FS, Wojtkiewicz GR, et al. Vascular and neurogenic rejuvenation of the aging mouse brain by young systemic factors. Science. 2014;344(6184):630-4.

[76] Villeda SA, Luo J, Mosher KI, Zou B, Britschgi M, Bieri G, et al. The ageing systemic milieu negatively regulates neurogenesis and cognitive function. Nature. 2011;477(7362):90-94.

[77] DeCarolis NA, Kirby ED, Wyss-Coray T, Palmer TD. The Role of the Microenvironmental Niche in Declining StemCell Functions Associated with Biological Aging. Cold Spring Harb Perspect Med. 2015;5(12).

[78] Bickford PC, Kaneko Y, Grimmig B, Pappas C, Small B, Sanberg CD, et al. Nutraceutical intervention reverses the negative effects of blood from aged rats on stem cells. Age (Dordr). 2015;37(5):103.

[79] Shetty AK, Hattiangady B, Shetty GA. Stem/progenitor cell proliferation factors FGF-2, IGF-1, and VEGF exhibit early decline during the course of aging in the hippocampus: Role of astrocytes. Glia. 2005;51(3):173-86.

[80] Carter LA, Roskams AJ. Neurotrophins and their receptors in the primary olfactory neuraxis. Microsc Res Tech. 2002;58(3):189-96.

[81] Lanfranco F, Gianotti L, Giordano R, Pellegrino M, Maccario M, Arvat E. Ageing, growth hormone and physical performance. J Endocrinol Invest. 2003;26(9):861-72.

[82] Enwere E, Shingo T, Gregg C, Fujikawa H, Ohta S, Weiss S. Aging results in reduced epidermal growth factor receptor signaling, diminished olfactory neurogenesis, and deficits in fine olfactory discrimination. J Neurosci. 2004;24(38):8354-65.

[83] Trejo JL, Carro E, Lopez-Lopez C, Torres-Aleman I. Role of serum insulin-like growth factor I in mammalian brain aging. Growth Horm IGF Res. 2004;14(Suppl A): S39-43.

[84] Abrous DN, Koehl M, Le Moal M. Adult neurogenesis: From precursors to network and physiology. Physiol Rev. 2005;85(2):523-69.

[85] Cotman CW. The role of neurotrophins in brain aging: A perspective in honor of Regino Perez-Polo. Neurochem Res. 2005;30(6-7):877-81.

[86] Mohapel P, Frielingsdorf H, Häggblad J, Zachrisson O, Brundin P. Platelet-derived growth factor (PDGF-BB) and brain-derived neurotrophic factor (BDNF) induce striatal neurogenesis in adult rats with 6-hydroxydopamine lesions. Neuroscience. 2005;132(3):767-76.

[87] Ehm O, Göritz C, Covic M, Schäffner I, Schwarz TJ, Karaca E, et al. RBPJkappa-dependent signaling is essential for long-term maintenance of neural stem cells in the adult hippocampus. J Neurosci. 2010;30(41):13794807.

[88] Mira H, Andreu Z, Suh H, Lie DC, Jessberger S, Consiglio A, et al. Signaling through BMPR-IA regulates quiescence and long-term activity of neural stem cells in the adult hippocampus. Cell Stem Cell. 2010;7(1):78-89.

[89] Bonaguidi MA, Song J, Ming G, Song H. A unifying hypothesis on mammalian neural stem cell properties in the adult hippocampus. Curr Opin Neurobiol. 2012;22(5):754-61.

[90] Kang W, Hébert JM. FGF signaling is necessary for neurogenesis in young mice and sufficient to reverse its decline in old mice. J Neurosci. 2015;35(28):10217-23.

[91] Wei Z, Salmon RM, Upton PD, Morrell NW, Li W. Regulation of bone morphogenetic protein 9 (BMP9) by redox-dependent proteolysis. J Biol Chem. 2014;289(45):31150-9.

[92] Chlan-Fourney J, Ashe P, Nylen K, Juorio AV, Li XM. Differential regulation of hippocampal BDNF mRNA by typical and atypical antipsychotic administration. Brain Res. 2002;954(1):11-20.

[93] Chen X, Li Y, Wang L, Katakowski M, Zhang L, Chen $\mathrm{J}$, et al. Ischemic rat brain extracts induce human marrow stromal cell growth factor production. Neuropathology. 2002;22(4):275-9.

[94] Scharfman H, Goodman J, Macleod A, Phani S, Antonelli $\mathrm{C}$, Croll S. Increased neurogenesis and the ectopic granule cells after intrahippocampal BDNF infusion in adult rats. Exp Neurol. 2005;192(2):348-56.

[95] Taliaz D, Stall N, Dar DE, Zangen A. Knockdown of brain-derived neurotrophic factor in specific brain sites precipitates behaviors associated with depression and reduces neurogenesis. Mol Psychiatry. 2010;15(1):80-92.

[96] Jessberger S, Clark RE, Broadbent NJ, Clemenson GD, Consiglio A, Lie DC, et al. Dentate gyrus-specific knockdown of adult neurogenesis impairs spatial and object recognition memory in adult rats. Learn Mem. 2009; 16(2):147-54

[97] Ko H-G, Jang D-J, Son J, Kwak C, Choi J-H, Ji Y-H, et al. Effect of ablated hippocampal neurogenesis on the formation and extinction of contextual fear memory. Mol Brain. 2009;2:1.

[98] Kesner RP, Hui X, Sommer T, Wright C, Barrera VR, Fanselow MS. The role of postnatal neurogenesis in supporting remote memory and spatial metric processing. Hippocampus. 2014;24(12):1663-71.

[99] Saxe MD, Battaglia F, Wang J-W, Malleret G, David DJ, Monckton JE, et al. Ablation of hippocampal neurogenesis impairs contextual fear conditioning and synaptic plasticity in the dentate gyrus. Proc Natl Acad Sci U S A. 2006;103(46):17501-6.

[100] Nagai T, Yamada K, Kim H-C, Noda Y, Nabeshima Y, Nabeshima T. [Cognition impairment in the klotho gene mutant mice and oxidative stress]. Nihon Shinkei Seishin Yakurigaku Zasshi. 2003;23(5):211-17.

[101] Wang D, Cui Z, Zeng Q, Kuang H, Wang LP, Tsien JZ, et al. Genetic enhancement of memory and long-term potentiation but not CA1 long-term depression in NR2B transgenic rats. PLoS One. 2009;4(10):e7486.

[102] Tang YP, Shimizu E, Dube GR, Rampon C, Kerchner GA, Zhuo M, et al. Genetic enhancement of learning and memory in mice. Nature. 1999;401(6748):63-9.

[103] Tovar KR, Westbrook GL. The incorporation of NMDA receptors with a distinct subunit composition at nascent 
hippocampal synapses in vitro. J Neurosci. 1999;19 (10):4180-8

[104] Cull-Candy SG, Leszkiewicz DN. Role of distinct NMDA receptor subtypes at central synapses. Sci STKE. 2004;2004(255):re16.

[105] Maltare A, Nietz AK, Laszczyk AM, Dunn TS, Ballestas ME, Accavitti-Loper MA, et al. Development and characterization of monoclonal antibodies to detect klotho. Monoclon Antib Immunodiagn Immunother. 2014;33(6):420-7.

[106] Park S-J, Shin E-J, Min SS, An J, Li Z, Hee Chung Y, et al. Inactivation of JAK2/STAT3 signaling axis and downregulation of M1 mAChR cause cognitive impairment in klotho mutant mice, a genetic model of aging. Neuropsychopharmacology. 2013;38(8):1426-37.

[107] Migaud M, Charlesworth P, Dempster M, Webster LC, Watabe AM, Makhinson $M$, et al. Enhanced long-term potentiation and impaired learning in mice with mutant postsynaptic density-95 protein. Nature. 1998;396(6710):433-9.

[108] Kosakai A, Ito D, Nihei Y, Yamashita S, Okada Y, Takahashi K, et al. Degeneration of mesencephalic dopaminergic neurons in klotho mouse related to vitamin D exposure. Brain Res. 2011;1382:109-17.

[109] Rodriguez M, Rodriguez-Sabate C, Morales I, Sanchez A, Sabate M. Parkinson's disease as a result of aging. Aging Cell. 2015;14(3):293-308.

[110] Brobey RK, German D, Sonsalla PK, Gurnani P, Pastor $\mathrm{J}$, Hsieh CC, et al. Klotho Protects Dopaminergic Neuron Oxidant-Induced Degeneration by Modulating
ASK1 and p38 MAPK Signaling Pathways. PLoS One. 2015;10(10):e0139914.

[111] Brobey RK, Dheghani M, Foster PP, Kuro-O M, Rosenblatt KP. Klotho Regulates 14-3-3 $\zeta$ Monomerization and Binding to the ASK1 Signaling Complex in Response to Oxidative Stress. PLoS One. 2015;10(10):e0141968.

[112] Baluchnejadmojarad T, Eftekhari S-M, Jamali-Raeufy N, Haghani S, Zeinali H, Roghani M. The anti-aging protein klotho alleviates injury of nigrostriatal dopaminergic pathway in 6-hydroxydopamine rat model of Parkinson's disease: Involvement of PKA/CaMKII/CREB signaling. Exp Gerontol. 2017;100:70-6.

[113] Toyama R, Fujimori T, Nabeshima Y, Itoh Y, Tsuji Y, Osamura RY, et al. Impaired regulation of gonadotropins leads to the atrophy of the female reproductive system in klotho-deficient mice. Endocrinology. 2006;147(1):120-9.

[114] Shahmoon S, Rubinfeld H, Wolf I, Cohen ZR, Hadani M, Shimon I, et al. The aging suppressor klotho: A potential regulator of growth hormone secretion. Am J Physiol Endocrinol Metab. 2014;307(3):E326-34.

[115] King GD, Chen C, Huang MM, Zeldich E, Brazee PL, Schuman ER, et al. Identification of novel small molecules that elevate Klotho expression. Biochem J. 2012;441(1):453-61.

[116] Brownstein CA, Adler F, Nelson-Williams C, Iijima J, Li P, Imura A, et al. A translocation causing increased alpha-klotho level results in hypophosphatemic rickets and hyperparathyroidism. Proc Natl Acad Sci U S A. 2008;105(9):3455-60. 